\title{
Adopt the latest trends in digital and aesthetic dentistry with the Nordic Institute of Dental Education
}

Digital innovations are becoming increasingly common and introduce several advantages compared to conventional methods. Digital technology provides an excellent return on investment, but needs to be efficiently implemented. Training and education play a key role in unlocking the full potential of new dental innovations. With the right type of guidance, dental professionals can conquer the learning curve effectively, and focus on what is truly important treating patients.

The Nordic Institute of Dental Education (NIDE), a joint venture of Planmeca and the University of Turku, offers a wide range of CE courses on various digital dentistry topics. The courses are an intriguing blend of theoretical and practical perspectives, complemented by fun activities outside the classroom. Most of the courses are held at the Planmeca Digital Academy training center in Helsinki where the latest technologies are available. NIDE courses are taught in English by leading experts in their fields. The courses have an international atmosphere, as NIDE has hosted dental professionals from 23 different countries over the past two years.

NIDE's courses cover a wide range of topics from digital imaging and $\mathrm{CAD} / \mathrm{CAM}$ to aesthetic and restorative dentistry, with its educational approach firmly rooted in digital dentistry. The courses on $3 \mathrm{D}$ imaging and $\mathrm{CAD} / \mathrm{CAM}$ have been especially popular, but indeed all courses have received praise from participants. Visitors have particularly appreciated the practical skills they have acquired, the expertise of the lecturers, and NIDE's forward-thinking approach to dentistry overall.

Croatian prosthodontist Dr Mirna Munitić from Poliklinika Bagatin attended her first NIDE course in May 2015 and said: 'I am able to utilise what I learned every day in my work. My clinic purchased a wide range of Planmeca equipment last year. At the time,

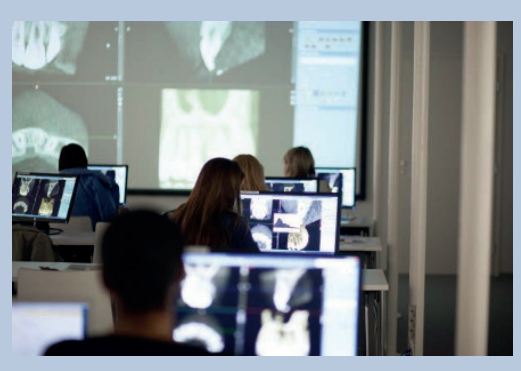
we were also told about the Nordic Institute of Dental Education and advised that its courses would help to make the most of our digital investment. So I decided to attend NIDE's 3D imaging and diagnostics course.
The Nordic Institute of Dental Education (NIDE) is a joint venture of Planmeca and the University of Turku. NIDE offers continuing education courses to international dental professionals looking to strengthen their expertise in digital and aesthetic dentistry. NIDE's programme features $3 \mathrm{D}$ and CAD/CAM courses targeting users of all levels - from beginners to intermediate and more advanced learners. NIDE courses are accredited in the European Credit Transfer system by the University of Turku. NIDE is also recognised by the American Dental Association's Continuing Education Recognition Program (ADA CERP).

'I was interested in the scientific approach of the course and read about its lecturers and their work in advance. They fully met my expectations and even exceeded them. The lecturers were so professional and knowledgeable - I really admired them for it.

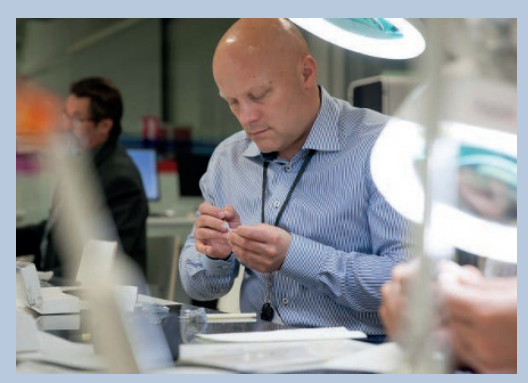

'It was also very nice to connect with colleagues from different parts of the world with such similar interests in their work as me. Sometimes professional congresses can have too many people, but NIDE's 3D course had a cosy group. It was great spending time together.

'I hadn't been to Finland before attending the course and didn't really know what to expect. I ended up enjoying my time there a lot. I liked the food and the city of Helsinki - the people there were so friendly. I even had a chance to try a traditional Finnish sauna!

'NIDE's course was a great experience overall. Everything was well organised and I was thrilled with the whole package. I came back home happy with lots of new information to use to improve my practice. I am able to utilise what I learned every day in my work.

'I would definitely recommend NIDE's courses. In fact, I already have - my colleague already went to the $3 D$ imaging and diagnostics course after I had praised it to him. We are heading back to Finland together for NIDE's Advanced 3D diagnostics course and looking forward to learning even more!'

\section{NIDE courses}

3D courses:

3D imaging and diagnostics Advanced 3D diagnostics $3 \mathrm{D}$ in maxillofacial surgery Digital dentistry summer school

\section{CAD/CAM courses:}

Fundamentals of CAD/CAM

Beyond the basics of CAD/CAM

Advanced CAD/CAM

Digital dentistry summer school
Other dentistry courses:

Aesthetic dentistry

Conservative approaches in

restorative dentistry

All about adhesion
New for 2017!

Digital Implant Workflow 